HUMANASE SOCIAIS

V.8 * N.1 • Abril/Maio/Junho - 2019

ISSN Digital: 2316-3801

ISSN Impresso: 2316-3348

DOI: 10.17564/2316-3801.2019v7n3p47-56
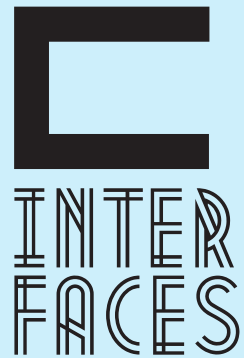

CIENTÍFICAS

\title{
A INCONSTITUCIONALIDADE DA INTERVENÇÃO FEDERAL REALIZADA NO ESTADO DO RIO DE JANEIRO
}

THE UNCONSTITUTIONALITY OF THE FEDERAL INTERVENTION HELD AT THE STATE OF RIODE JANEIRO

LA INCONSTITUCIONALIDADDE LA INTERVENCIÓN FEDERAL EN EL ESTADODE RÍODE JANEIRO

Luiz Francisco de Oliveira ${ }^{1}$

Tarsis Barreto Oliveira ${ }^{2}$

\section{RESUMO}

0 presente artigo tem por escopo analisar o instituto da intervenção federal, discorrendo sobre as suas diferentes espécies, bem como demonstrar que a intervenção ocorrida no Rio de Janeiro não obedeceu aos comandos constitucionais. Segundo a Constituição de 1988, a intervenção federal foi idealizada com o fulcro de evitar deturpações na ordem interna, protegendo a forma federativa contra abusos que põem em xeque a higidez constitucional. Para atingir tal desiderato foram feitas pesquisas em doutrinas, legislação e jurisprudência, chegando-se à conclusão de que intervenção com consenso não é admitida na Constituição Federal, existindo meio alternativo para solucionar o problema: a aplicação da Lei nº 11.473/2007.

\section{PALAVRAS-CHAVE}

Intervenção Federal. Rio de Janeiro.

Inconstitucionalidade. 


\section{ABSTRACT}

The purpose of this article is to analyze the institute of federal intervention, discussing its different species, as well as to demonstrate that the intervention occurred in Rio de Janeiro did not obey the constitutional commands. According to the 1988 Constitution, federal intervention was idealized with the focus of avoiding misrepresentations in the domestic order, protecting the federative form against abuses that call into question constitutional firmness. In order to achieve this goal, research was done on doctrines, legislation and jurisprudence, reaching the conclusion that intervention with consensus is not allowed in the Federal Constitution, and there is an alternative way to solve the problem: the application of Law 11.473/2007.

\section{KEYWORDS}

Federal Intervention. Rio de Janeiro. Unconstitutionality.

\section{RESUMEN}

Este artículo tiene como objetivo analizar el instituto de la intervención federal, discutiendo sus diferentes especies, así como demostrar que la intervención tuvo lugar en Río de Janeiro no obedecía las órdenes constitucionales. Según la Constitución de 1988, la intervención federal se fraguó con el fulcro para evitar malas interpretaciones en el orden interno, proteger la forma federativa contra abusos que ponen en cuestión la salud constitucional. Para lograr este requisito, se hizo investigación en la doctrina, legislación y jurisprudencia, llegándose a la conclusión de que la intervención con el consenso no es admitida en la Constitución Federal, existen medios alternativos para resolver el problema: la aplicación de la Ley $n^{\circ} 11.473 / 2007$.

\section{PALABRAS CLAVE}

Intervención federal. Río de Janeiro. Inconstitucionalidad. 


\section{INTRODUÇ̧̃̃o}

Procedeu-se recentemente no estado do Rio de Janeiro a uma intervenção federal baseada no consenso, esculpida ao arrepio da Constituição Cidadã, tendo anuído o governador do Estado do Rio de Janeiro à proposta feita pelo Presidente da República. Conforme será demonstrado no presente trabalho, a ordem constitucional brasileira não prevê a intervenção baseada no consenso, até porque, se houver consenso, basta aplicar um outro meio alternativo para solucionar o problema: in casu, a Lei no 11.473/2007.

Todos, provavelmente sem exceção, desde o cidadão comum até o homem mais letrado, admitem que o sistema de segurança pública está carcomido: sua ineficiência é alarmante e, sem dúvida, a todos assusta. As consequências da falta de medidas eficazes no combate à violência deixam a sociedade em alerta. A situação do Rio de Janeiro, no que concerne à segurança pública, não foge à regra: o crime organizado, aproveitando-se da inércia estatal, dominou a sociedade carioca, comprovando a máxima de que não há vácuo de poder quando o Estado e suas instituições não se fazem presentes.

Baseado na constatação factual de que a criminalidade atingiu níveis alarmantes, o Presidente Michel Temer decretou a intervenção federal no estado do Rio de Janeiro. O Presidente da República fez uso da atribuição que lhe confere o artigo 84, caput, inciso X, da Constituição Federal de 1988, decretando a intervenção federal até o dia 31 de dezembro de 2018. A intervenção federal se limita à área de segurança pública e tem como objetivo pôr termo ao grave comprometimento da ordem pública no Estado do Rio de Janeiro. Para isso foi nomeado como Interventor o general de Exército Walter Souza Braga Netto, Comandante Militar do Leste (CML), para exercer cargo de natureza militar.

No decreto consta que o general ficará diretamente subordinado ao Presidente da República, não estando sujeito às normas estaduais que conflitarem com as medidas necessárias à execução da intervenção, podendo requisitar, se necessário, os recursos financeiros, tecnológicos, estruturais e humanos do Estado do Rio de Janeiro para a consecução do objetivo da intervenção.

0 presente artigo tem por escopo analisar o instituto da intervenção federal, discorrendo sobre as suas diferentes espécies, bem como demonstrar que a intervenção ocorrida no Rio de Janeiro não obedeceu aos comandos constitucionais.

\section{PRINCIPAIS ASPECTOS DA INTERVENÇÃO FEDERAL}

O instituto da intervenção federal, presente em todas as Constituições republicanas, representa um elemento fundamental na própria formulação da doutrina do federalismo, que dele não pode prescindir inobstante a expecionalidade de sua aplicação, para efeito de preservação da intangibilidade do vínculo federativo, da unidade do Estado Federal e da integridade territorial das unidades federadas. A invasão territorial de um Estado por outro constitui um dos pressupostos de admissibilidade da intervenção federal (BRASIL, 1992). 
O presidente da República, ao utilizar da prerrogativa constitucional da intervenção federal, age de forma discricionária, sendo que a situação posta em exame se sujeita ao seu livre juízo político, não estando subordinado ao Poder Judiciário ou mesmo a qualquer outro Poder. Havendo o decreto presidencial de intervenção federal, este deverá ser submetido à apreciação do Congresso Nacional no prazo de vinte e quatro horas e, mesmo que o Congresso se encontre em recesso, deverá ser convocado extraordinariamente, no prazo de vinte e quatro horas.

Apesar da decisão do Presidente da República ser política, a intervenção está sujeita aos controles de legalidade e de constitucionalidade, podendo a medida ser alvo de ações junto ao Poder Judiciário.

Em países onde vigora o Estado Democrático de Direito, o uso do poder das Forças Armadas, constituídas pelo Exército, Marinha e Aeronáutica, só pode ocorrer sob ordem dos poderes constituídos, isto é, dos conselhos formados por membros do Poder Executivo e do Poder Legislativo e com a devida supervisão do Poder Judiciário. De acordo com a nossa Magna Carta, as intervenções só podem ocorrer em três casos específicos: Intervenção federal, Estado de defesa e Estado de sítio. Isto ocorre devido ao princípio do Pacto Federativo (art. 18), onde os quatro Entes Federativos (União, Estados, Municípios e Distrito Federal) são autônomos, autogovernáveis, (podem escolher, por meio de eleição, seus chefes do Executivo e do legislativo) auto-organizáveis (expressa no poder de elaborar sua Constituição) e normas estaduais autoadministráveis (têm competências administrativas e tributos próprios)

É uma medida excepcional, pois só pode ser tomada em situações extraordinárias, em que é suprimida temporariamente a autonomia assegurada aos Estados, Distrito Federal e Municípios pela Constituição Federal, em consequência de situação de anormalidade previamente definida na Carta Maior.

O seu escopo é buscar a normalidade da democracia e das leis. Tal fato se deve à necessária observância do princípio constitucional republicano, onde deve prevalecer a vontade da maioria. No fundo, o que se promove com o instituto da intervenção é o pleno funcionamento da democracia.

Como todo princípio constitucional, ele não é absoluto. Em condições normais, o governo federal não pode intervir nos Estados; porém o artigo 34, que regula o procedimento, traz situações em que isso pode ocorrer, havendo uma situação excepcional em que a autonomia dos Entes Federativos é temporariamente suprimida para que a ordem e o Estado Democrático de Direito prevaleçam.

O artigo 34 da Constituição Federal de 1988, preconiza que

Art. 34. A União não intervirá nos Estados nem no Distrito Federal, exceto para:

I - manter a integridade nacional;

II - repelir invasão estrangeira ou de uma unidade da Federação em outra;

III - pôr termo a grave comprometimento da ordem pública;

IV - garantir o livre exercício de qualquer dos Poderes nas unidades da Federação;

$V$ - reorganizar as finanças da unidade da Federação que:

A) suspender o pagamento da dívida fundada por mais de dois anos consecutivos, salvo motivo de força maior;

b) deixar de entregar aos Municípios receitas tributárias fixadas nesta Constituição, dentro dos prazos estabelecidos em lei;

VI - prover a execução de lei federal, ordem ou decisão judicial; 
VII - assegurar a observância dos seguintes princípios constitucionais:

a) forma republicana, sistema representativo e regime democrático;

b) direitos da pessoa humana;

c) autonomia municipal;

d) prestação de contas da administração pública, direta e indireta.

A intervenção federal pode ser decretada pelo Presidente da República, por iniciativa própria ou por solicitação do Poder Legislativo, de alguma instância superior do Judiciário, especificamente o Supremo Tribunal Federal (STF), o Superior Tribunal de Justiça (STJ) ou o Tribunal Superior Eleitoral (TSE), ou por solicitação da Procuradoria-Geral da República provida pelo STF.

Em todas as situações de intervenção federal o decreto é de competência do presidente da República. Nas situações em que a intervenção não é requisitada pelo Judiciário, o presidente pode agir, atendendo a critérios de conveniência e oportunidade. Isso porque, quando a intervenção for requisitada pelo Poder Judiciário, ela não deixa de ter natureza político-administrativa.

A Constituição Federal nos revela várias espécies de intervenção federal, sendo espontânea quando o Presidente da República age de ofício, conforme consta no artigo $34^{\circ}$, incisos I, II, III e IV da Constituição Federal. O Presidente da República, dentro de seu juízo de discricionariedade, decide pela intervenção e, de ofício, executa-a, independentemente de provocação de outros órgãos. São hipóteses de intervenção espontânea: para a defesa da unidade nacional (CF/88, art. 34, I e II); para a defesa da ordem pública (CF/88, art. 34, III); para a defesa das finanças públicas (CF/88, art. 34, V).

Interessante observar a necessidade de consulta dos Conselhos da República e Defesa Nacional, conforme dispõem os artigos 90 , I e $91, \S 1^{\circ}$, II, da CF/88, mesmo que não crie qualquer vinculação para o chefe do executivo.

A intervenção será provocada por solicitação quando recair coação ou impedimento dos Poderes Legislativo ou Executivo, de exercerem suas atividades nas unidades federativas. Consoante a CF/88, no artigo $34^{\circ}$, inciso IV, combinado com o artigo $36^{\circ}$, inciso I, primeira parte, tais Poderes dos Estados deverão solicitar o decreto da intervenção federal.

Situação interessante ocorre quando a coação for exercida contra o Poder Judiciário. Neste caso, a decretação da intervenção será provocada e dependerá de requisição ao Supremo tribunal Federal, conforme preceitua o artigo $34^{\circ}$, inciso IV, combinado com o artigo $36^{\circ}$, inciso I, segunda parte. Situação semelhante ocorrerá quando houver desobediência a ordem ou decisão judicial emanadas dos Tribunais superiores: STF, STJ ou TSE. Assim sendo, a decretação da intervenção federal dependerá de requisição do Tribunal Superior, de acordo com a matéria, conforme os dizeres do artigo 34, inciso $\mathrm{VI}$, segunda parte, combinado com o artigo $36^{\circ}$, inciso II da CF/88.

Por fim, tem-se a situação da intervenção provocada, dependendo do provimento de representação do Procurador-Geral da República. Tal intervenção ocorrerá em duas situações: no caso de ofensa aos princípios constitucionais sensíveis, previstos no artigo $34^{\circ}$, inciso VII da CF/88, a intervenção federal dependerá de provimento, pelo STF, de representação do Procurador-Geral da República, conforme preconizado no artigo $34^{\circ}$, inciso VII combinado com o artigo $36^{\circ}$, inciso III, primeira parte, e para prover a execução de lei federal a intervenção dependerá de provimento de representação do 
Procurador-Geral da República pelo STF. Tal situação está regulada no artigo $34^{\circ}$, inciso VI, primeira parte, combinado com o artigo $36^{\circ}$, inciso III, segunda parte.

Devido ao pacto federativo, as hipóteses de intervenção estadual e federal (em municípios localizados em Territórios Federais), também, estão previstas na Carta Magna, notadamente no artigo 35, sendo cabíveis quando: a dívida fundada deixar de ser paga, sem motivo de força maior, por 2 anos consecutivos; não forem prestadas as contas devidas, na forma da lei; quando o município do Estado ou do Território Federal deixar de aplicar o mínimo exigido da receita municipal na manutenção e desenvolvimento do ensino e nas ações e serviços de saúde; ou quando Tribunal de Justiça der provimento à representação de princípios indicados na Constituição Estadual, ou para prover a execução de lei, de ordem ou decisão judicial.

Interessante observar que os Tribunais de Contas não podem requerer ao governador do Estado a intervenção em Município, pois o Tribunal de Contas age como auxiliar do Legislativo municipal, a este cabendo formular a representação, se não rejeitar, por decisão de dois terços dos seus membros, o parecer prévio emitido pelo Tribunal (CF, art. $\left.31, \S 2^{\circ}\right)$. Tal entendimento foi pacificado no julgamento da ADI 2.631, rel. min. Carlos Velloso (j. 29-8-2002, P, DJ de 8-8-2003).

Como a intervenção estadual em Município tem natureza político-administrativa, o STF sumulou o entendimento de que não cabe recurso extraordinário contra acórdão de Tribunal de Justiça que defere pedido de intervenção estadual em Município (SÚMULA 637).

\section{DA INCONSTITUCIONALIDADE DA INTERVENÇÃO FEDERAL NO ESTADO DO RIO DE JANEIRO}

A intervenção federal que ocorreu no estado do Rio de Janeiro já nasce sob o signo da inconstitucionalidade. O artigo 21 da Constituição Federal de 1988 preconiza que compete à União

Decretar o estado de sítio, o estado de defesa e a intervenção federal. No artigo 34 consta que a União não intervirá nos Estados nem no Distrito Federal, exceto para: [...] III - pôr termo a grave comprometimento da ordem pública.

Este é o verdadeiro objetivo do decreto de intervenção. Já no artigo 36, parágrafo $4^{\circ}$, é preconizado que cessados os motivos da intervenção, as autoridades afastadas de seus cargos a estes voltarão, salvo impedimento legal.

A Constituição da República, em seu artigo 36, parágrafo $1^{\circ}$ determina expressamente que sejam especificados a amplitude, o prazo e as condições de execução. Como as medidas adotadas na intervenção serão precipuamente aplicadas na segurança pública, há grandes possibilidades de atingir direitos fundamentais capitulados no artigo $5^{\circ}$ da Constituição Federal de 1988.

Paradoxalmente, foi dado ao interventor mera delegação geral para a adoção de medidas inespecíficas. Tanto isso é verdade que o decreto de intervenção no Rio de Janeiro não capitula quaisquer medidas a serem adotadas. De forma bastante genérica, o que não convém a um decreto interventivo, no artigo 
$3^{\circ}$ do supramencionado Decreto, consta que as atribuições do interventor serão as mesmas constantes no art. 145 da Constituição do Estado do Rio de Janeiro necessárias às ações de segurança pública, previstas no Título V da Constituição do Estado do Rio de Janeiro. 0 decreto interventivo falou tudo e não descreveu nada, omitindo-se quanto à menção de quais as medidas interventivas que o interventor adotaria, lembrando que as medidas gerais já constam na Constituição Estadual do Rio de Janeiro.

Outro detalhe discrepante: o artigo $2^{\circ}$, parágrafo único, do Decreto preconiza que [o] cargo de Interventor é de natureza militar. Ocorre que em momento algum a Constituição Federal determina que o cargo de interventor seja de natureza militar. Se as próprias Forças Armadas são diretamente subordinadas a um ministro civil (Ministro de Estado da Defesa), mais conveniente que a segurança pública seja também subordinada a um civil.

Em vários estados da Federação a Secretaria de Defesa Social é responsável pelos trabalhos da Polícia Militar e Civil e são chefiadas por civis. É bem provável que o Presidente da República queira que o interventor nomeado não responda por eventuais crimes cometidos no cargo na Justiça comum. Ademais, por questões lógicas, o interventor pode até ser militar, mas deve se submeter à jurisdição civil. Deixar nas mãos da Justiça Castrense o julgamento dos atos do interventor é um verdadeiro atentado à Constituição, pois subtrai do Poder Judiciário atos de autoridade civil. Se, em regra, os membros da Polícia civil só respondem perante a Justiça Comum, como o seu comandante pode não responder?

É forçoso convir que qualquer intervenção federal nos Estados é caracterizada por afastar e substituir a autonomia estadual. Como substituto do Governo no Estado, seus atos são praticados no exercício da gestão estadual. 0 objetivo de toda e qualquer intervenção é afastar a autoridade estadual e substituir a mesma pela figura do interventor.

Consta no artigo 60, parágrafo $1^{\circ}$ que a Constituição não poderá ser emendada na vigência de intervenção federal, de estado de defesa ou de estado de sítio. É fácil entender os motivos que levaram o Poder Constituinte Originário a assentar tal limitação. Imagine o Brasil, passando por uma das situações constitucionais que mereçam algum tipo de intervenção, semelhante ao que está ocorrendo nesse momento. Será mesmo o momento mais oportuno para se alterar o texto da constituição? Percebe-se de maneira cabal que a instabilidade do momento não é adequada à proposição de mudança do texto constitucional, dado o seu limite circunstancial.

Lado outro, é sabido que o Governo Federal está lutando para aprovar a Proposta de Emenda Constitucional da Previdência. Alega o Presidente da República que se tiver votos para aprovar a reforma, o decreto pode ser cessado e após a votação ser novamente reiniciado. Essa medida é flagrantemente inconstitucional, causando ainda mais perplexidade saber que tal alegação partiu de famoso constitucionalista brasileiro: o próprio presidente da República.

Em meio a várias inconstitucionalidades, necessário observar que o Presidente da República não consultou o Conselho da República e nem o Conselho de Defesa Nacional. A Lei nº 8.04190, em seu artigo $2^{\circ}$, inciso I, menciona que compete ao Conselho da República pronunciar-se sobre: a intervenção federal. Os artigos 90 , inciso I, e 91 , parágrafo $1^{\circ}$, inciso I, atribuem a esses órgãos competência para opinar sobre intervenções federais, e tal consulta deve ser feita antes da edição do decreto de 
intervenção. O Presidente da República, de fato, não é obrigado a seguir a opinião dos Conselhos, mas é obrigatório o pronunciamento prévio.

A função do Conselho da República e do Conselho de Defesa Nacional é exercer o controle social. Apesar das opiniões dos referidos Conselhos não vincular o Presidente da República, suas oitivas são exigências estabelecidas em nossa Carta Magna, pois envolvem a participação de representantes do povo, o que é fulcral no Estado democrático de direito.

Por isso, é inválido o decreto de intervenção que não tenha sido precedido da convocação e reunião dos Conselhos da República e de Defesa Nacional.

No desenrolar da intervenção, foi aventado a utilização de mandados coletivos de busca e apreensão. Conforme Galindo (2018, p. 54),

Acaso isso venha a ocorrer, é um desdobramento claramente inconstitucional da intervenção federal, já que mesmo na vigência desta última, como lembrei acima, os direitos e garantias fundamentais são plenamente aplicáveis e, assim sendo, não há qualquer autorização legal ou constitucional para esse tipo anômalo de mandado judicial.

Leonardo Isaac Yarochewsky (2018, on-line), em artigo publicado na internet, aduz que

No Título que trata Dos Direitos e Garantias Fundamentais da Constituição da República (CR) está assentado que: a casa é asilo inviolável do indivíduo, ninguém nela podendo penetrar sem consentimento do morador, salvo em caso de flagrante delito ou desastre, ou para prestar socorro, ou, durante o dia, por determinação judicial' (art. 5, inc. XI da CR). (Grifo no original).

No Manifesto publicado pela Assessoria de Imprensa do Gabinete do Reitor da Universidade Federal do Rio de Janeiro (UFRJ-2018), assinado por mais de 300 acadêmicos, artistas, intelectuais, políticos, juristas e movimentos sociais (UFRJ, 2018, on-line), seus autores alegam que

No contexto da grave crise política, econômica e institucional que vive o país e ameaça a nossa soberania, as manifestações de autoridades civis e militares reivindicando amplos poderes e salvo-conduto para o exercício ilimitado da violência pelas forças de intervenção contra suspeitos provocam perplexidade e nosso absoluto repúdio.

No dia 16 de fevereiro de 2018 foi assinado o decreto que nomeou como interventor na segurança fluminense o general do Exército Walter Braga Netto. De lá para cá, ocorreram crimes que não foram ainda desvendados, demonstrando que a propaganda ilusória divulgada não atingiu o seu desiderato.

Segundo a ONG Fogo Cruzado (2018), que mantém um mapa que registra confrontos, envolvendo armas de fogo no Rio de Janeiro e região metropolitana,

Foram registrados 743 tiroteios ou disparos de armas de fogo na região entre 16 de fevereiro data da assinatura do decreto de intervenção e 18 de março. 0 número é superior

Interfaces Científicas - Humanas e Sociais - Aracaju • V.8 - N.1 • p. 111 - 122 - Abril/Maio/Junho - 2019 
ao período de 30 dias anterior à assinatura da medida, quando foram registrados 715 tiroteios e disparos. O levantamento ainda aponta que o número de mortes aumentou $19 \%$ foram 152 mortes no último mês, ante 127 entre 16 de janeiro e 16 de fevereiro.

Por fim, deve ser mencionado que desde os anos 1990, todos os presidentes fizeram uso das Forças Armadas para conter violência no estado, com resultados decepcionantes. Um editorial do jornal Folha de S. Paulo (1995) fez um julgamento severo:

Poucos resultados efetivos e muito abuso de autoridade. É assim que se pode definir a primeira intervenção mais direta do Exército no combate à criminalidade no Rio. A ação dos militares não resultou em muito mais do que boas cenas para cinegrafistas e fotógrafos e transtorno para os moradores.

\section{CONSIDERAÇÕES FINAIS}

A intervenção federal decretada recentemente no Rio de Janeiro não encontra respaldo constitucional. Acrescente-se a isso o fato de que anteriormente à sua decretação, esta foi anunciada pela imprensa, com direito a fotos e entrevistas, tendo o Governador do Rio de Janeiro participado da reunião com o Presidente da República para decidir a forma de sua realização. Não houve afastamento do governador, sendo que, paradoxalmente, a maior autoridade do Estado a ser alvo da intervenção concordou com ela.

Intervenção com consenso não é admitida na Constituição Federal de 1988, até porque se houve concordância, havia um meio alternativo previsto em lei para solucionar o problema. Se a União queria colaborar com a segurança pública do Estado do Rio de Janeiro não precisaria de qualquer decreto interventivo. Bastaria ao Presidente da República aplicar as leis, tal como a Lei ${ }^{0}$ 11.473/2007, que em seu artigo $4^{\circ}$, parágrafo único, prevê que a União, por intermédio do Ministério da Justiça, poderá colocar à disposição dos Estados e do Distrito Federal, em caráter emergencial e provisório, servidores públicos federais, ocupantes de cargos congêneres e de formação técnica compatível.

Não se deve admitir que a Constituição seja utilizada apenas como moeda política, sob pena de risco ao Estado Democrático de Direito, visto serem banalizados os institutos que a própria Constituição criou para dar maior garantia ao cidadão.

No episódio aqui relatado, as medidas implantadas são meramente paliativas, extremamente caras e sem nenhum impacto na violência, não tendo havido planejamento prévio. Receia-se que se promova uma falsa sensação de segurança, com os criminosos, atravessando a fronteira do Estado do Rio de Janeiro, levando violência para os Estados vizinhos, tal como ocorreu por ocasião da implantação das UPP. Posteriormente, retornarão aos seus redutos, recaindo as despesas de toda a logística implementada sobre o povo brasileiro. 


\section{REFERÊNCIAS}

BRASIL. Presidência da República. Lei n. 8.041, de 5 de junho de 1990. Dispõe sobre a organização e o funcionamento do Conselho da República. Disponível em: http://www.planalto.gov.br/ccivil_03/ Leis/L8041.htm. Acesso em: 27 maio 2018.

BRASIL. Presidência da República. Lei n. 8.183, de 11 de abril de 1991. Dispõe sobre a organização e o funcionamento do Conselho de Defesa Nacional e dá outras providências. Disponível em: http:// www.planalto.gov.br/ccivil_03/Leis//8183.htm. Acesso em: 26 maio 2018.

BRASIL. Presidência da República. Lei n. 11.473, de 10 de maio de 2007. Dispõe sobre cooperação federativa no âmbito da segurança pública e revoga a Lei no 10.277, de 10 de setembro de 2001. Disponível em: http://www.planalto.gov.br/ccivil_03/_ato2007-2010/2007/lei/l11473.htm. Acesso em: 26 maio 2018.

BRASIL. Supremo Tribunal Federal. Mandado de Segurança n. 21041 - RO. Impetrante: Governo do Estado de Rondônia. Impetrados: Governador do Estado do Acre, Ministro da Justiça e Presidente da República. Relator: Min. Celso de Melo. j. 12-6-1991, P, DJ de 13 março 1992.

FERRAZ, Anna Cândida da Cunha. Conflito entre poderes: o poder congressual de sustar atos normativos do Poder Executivo. São Paulo: Revista dos Tribunais, 1994.

GALINDO, Bruno. No olho do furacão: federalismo, intervenção e direitos fundamentais. Disponível em: http://justificando.cartacapital.com.br/2018/02/23/no-olho-do-furacao-federalismointervencao-e-direitos-fundamentais/. Acesso em: 23 jun. 2018.

JORNAL FOLHA DE SÃO PAULO. Exército no Rio: 25 anos de fracassos. Disponível em: https:// noticias.uol.com.br/ultimas-noticias/deutschewelle/2018/02/27/exercito-no-rio-25-anos-defracassos.htm. Acesso em: 17 maio 2018.

\section{LEWANDOWSKI, Ricardo Enrique. Pressupostos materiais e formais da intervenção federal no} Brasil. 2. ed. Belo Horizonte, MG: Editora Fórum. 2018.

MENDES, Gilmar Ferreira; COELHO, Inocêncio Mártires; BRANCO, Paulo Gustavo Gonet. Constituição da República, art. 90, I, e art. 91, § 1 II; Lei 8.041/1990, art. $2^{\circ}$, I; Curso de direito constitucional. 2. ed. São Paulo: Saraiva, 2008.

MORAES, Alexandre de. Direito constitucional. 10. ed. São Paulo: Atlas, 2001. 
ONG FOGO CRUZADO. Intervenção no Rio completa um mês sem resultados efetivos. Disponível em: http://www.dw.com/pt-br/interven\%C3\%A7\%C3\%A3o-no-rio-completa-um-m\%C3\%AAs-semresultados-efetivos/a-43031679. Acesso em: 24 maio 2018.

ROTHENBURG, Walter Claudius. Constituição da República, art. 60, § 10; Direito constitucional. São Paulo: Verbatim, 2010.

SILVA, José Afonso da. Curso de direito constitucional positivo. 16. ed. São Paulo: Malheiros, 1999.

SLAIBI Filho, Nagib. Anotações à Constituição de 1988: aspectos fundamentais. 4. ed. Rio de Janeiro: Forense, 1993.

TAVARES, André Ramos. Curso de direito constitucional. 13. ed. São Paulo: Saraiva, 2015.

TEMER, Michel. Elementos de direito constitucional. 10. ed. São Paulo: Malheiros,1993.

UFRJ - Universidade Federal do Rio de Janeiro. Manifesto sobre a intervenção federal e militar no Rio de Janeiro. Disponível em: https://ufrj.br/noticia/2018/03/02/manifesto-sobre-intervencaofederal-e-militar-no-rio-de-janeiro. Acesso em: 22 junho 2018.

YAROCHEWSKY, Leonardo Isaac. Mandado de busca e apreensão coletivo viola direitos e garantias fundamentais. Disponível em: http://justificando.cartacapital.com.br/2018/02/20/mandado-debusca-apreensao-coletivo-viola-direitos-e-garantias-fundamentais/. Acesso em: 23 jun. 2018. 
1 Mestrando em Prestação Jurisdicional e Direitos Humanos pela Universidade do Tocantins - UFT. Email: Iuizfrancisco.oliveira2011@uol.com.br

2 Doutor e Mestre em Direito pela UFBA; Professor Adjunto de Direito da UFT e UNITINS; Professor do Mestrado em Prestação Jurisdicional e Direitos Humanos da UFT/ESMAT. Email: luizfrancisco.oliveira2011@uol.com.br

\section{(a) (1) (2)}

Este artigo é licenciado na modalidade acesso abertosob a Atribuição-Compartilhalgual CC BY-SA

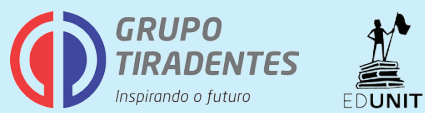

